Revista

A Cor

das Letras

\title{
Léxico e cultura: as denominações das culturas agrícolas do feijão e do milho por agricultores do município de Ocara-CE
}

\section{Lexicon and culture: the names of agricultural culture of bean and corn by Ocara's farmers in Ceará}

Francisco Cleziano Mendes de Lima*

Universidade Estadual do Ceará

Quixadá, Ceará, Brasil

Expedito Eloísio Ximenes**

Universidade Estadual do Ceará

Fortaleza, Ceará, Brasil

\begin{abstract}
Resumo: O presente artigo objetivou levantar e analisar as formas de nomear as culturas agrícolas, por trabalhadores rurais do município de Ocara-Ceará, especificamente as culturas do feijão e do milho. Para tanto, foi coletado um corpus, por meio de entrevistas realizadas com 6 agricultores. Apresentamos as lexias informadas pelos entrevistados, as interpretações e as análises do léxico que fizemos à luz dos métodos filológicos, especificamente o método Wörter und Sachen (Palavras e Coisas) e o Onomasiológico, desenvolvidos pelos romanistas no final do século XIX. Os teóricos que aplicaram os tais métodos consideram a língua oral, as vivências e o conhecimento de mundo dos sujeitos como elementos fundamentais para a nomeação das coisas, dos objetos, das práticas etc. e para o enriquecimento vocabular das línguas. Isso é importante para estabelecermos a relação corrente entre língua, léxico e cultura.
\end{abstract}

Palavras-Chave: Léxico. Cultura. Método Onomasiológico. Método Palavras e Coisas.

\begin{abstract}
This article aimed to select and analyse the ways country workers name the agricultural cultures in Ocara-Ceará, mainly the cultures of bean and corn. Therefore, a corpus was colected by intrviewing six farmers. We present the lexicon items the interviewees informed, the interpretations and the analyses of the lexicon we proceeded according to the philological methods, specially the Wörter und Sachen method ("Words and Things") and the Onomasiological one, developed by the romanists at the end of the XIX century. The theorists recognized for applying these methods consider the oral language, the life experiences as well as people's world knowledge as fundamental elements for naming things, objects, practices etc. as also for the vocabular enrichment of languages. It is important for setting up the relations that connect language, lexicon and culture.
\end{abstract}

Keywords: Lexicon. Culture. Onomasiological Method. Method Words and Things.

* Graduado em Letras/Português pela Faculdade de Educação, Ciências e Letras do Sertão Central (FECLESC), da Universidade Estadual do Ceará (UECE), Quixadá, Ceará, Brasil. E-mail: clezianolim@hotmail.com.

**Doutor em Letras, professor da Universidade Estadual do Ceará. E-mail: eloisio22@hotmail.com. 


\section{INTRODUÇÃO}

O ser humano é um inventor e um inovador por natureza. E a língua é o instrumento primeiro de expressão da sua alma, das suas emoções, de seus conhecimentos e de sua capacidade de comunicação. Tudo isso é possível porque a cultura ou o jeito de viver e de sentir o mundo é o fio condutor de todas as manifestações humanas. Uma dessas manifestações é a capacidade de nomear tudo que está ao redor dos sujeitos históricos e a forma criativa e comparativa do meio na influência dos atos culturais.

Pensando nas formas dos homens interagirem com seu meio, transformando-o e criando formas de dar nome às suas atividades e à produção, desenvolvemos este trabalho como uma pequena amostra desses recursos, cujo objetivo é realizar o levantamento e a análise das formas de nomear as culturas agricolas no município de Ocara, especificamente os tipos de feijão e de milho cultivados durante o período chuvoso pelos pequenos agricultores. Por meio de entrevistas de campo ${ }^{1}$ concedidas por eles, senhores residentes na zona rural do município, levantamos as lexias com as quais denominam essas culturas que cultivam e formamos nosso corpus de estudo.

Ocara é um município do estado do Ceará, localizado na Mesorregião Norte cearense e na Microrregião de Chorozinho, situado a 100 quilômetros da capital, Fortaleza, com população estimada de 25 mil habitantes, tendo sido emancipado politicamente em 1987, do município de Aracoiaba.

O topônimo Ocara vem do tupi-guarani e significa palco, terreiro ou terraço de aldeia ou taba. A economia do município é baseada na pecuária e na agricultura de subsistência, praticada por pequenos agricultores durante o período chuvoso, que compreende os meses de janeiro a maio. Devido às especificidades climáticas e geográficas dessa região, predomina o plantio de feijão e de milho para o consumo familiar, mas também se destaca o cultivo de caju, que garante uma boa renda no período da safra da castanha de setembro a dezembro.

Como mencionado anteriormente, o corpus foi obtido por meio de entrevistas com 6 agricultores da zona rural desse município. Durante a realização das entrevistas, embora direcionando as indagações, a prática utilizada foi deixar cada informante à vontade em sua fala, para que as informações surgissem de forma espontânea, contribuindo para o enriquecimento dos dados, quando procuramos anotar tudo fiel e minuciosamente.

Para a realização das entrevistas, deslocamo-nos a algumas localidades rurais do município e a bairros da cidade, como o Assentamento Fazenda Novas Vidas, a

\footnotetext{
${ }^{1}$ A presente pesquisa está inserida no Projeto Lingua e Cultura: as realidades de linguagem do Ceará, aprovado pelo Comitê de Ética em Pesquisa com Seres Humano da Universidade Estadual do Ceará, sob o parecer nº. 1.875.961 e CAAE No. 60475316.9.0000.5534.
} 
Comunidade do Alto Vermelho, o distrito de Curupira, o Bairro Boa Esperança e o Bairro Prainha, todos pertencentes à circunscrição do município de Ocara.

Entre os informantes, somente um não reside desde o nascimento no município, no entanto, todos têm a agricultura como profissão desde sempre, alguns já aposentados, outros não, compreendendo uma faixa etária média entre 51 a 72 anos de idade, sendo todos do sexo masculino.

Para selecionarmos os sujeitos informantes, consideramos dados como idade, sexo e tempo que mora na localidade. Nossa pesquisa centralizou-se em quatro perguntas que nos nortearam para a obtenção dos dados: Quais tipos de feijão o senhor conbece? Por que são denominados dessa forma? Quais tipos de milho o senhor conbece? Por que são denominados dessa forma?

Identificamos no corpus uma variação bem maior para as denominações do feijão, um total de 23, e para o milho 11, somando 34 lexias diferentes. Porém, o total geral da pesquisa, incluindo as repetidas, foram contabilizas 69 formas de nomear.

A análise dos dados teve como embasamento teórico os métodos usados pela Filologia Românica: Wörter und Sachen ou Palavras e coisas e o Onomasiológico, originários da Geografia Linguística, que se ocupou com a situação em que uma língua se encontra em determinado momento, localidade ou região, focalizado a língua oral, considerando o mundo real, as vivências, as práticas de trabalho e os costumes dos indivíduos. Métodos esses que foram de fundamental importância em nossa análise por considerarem a cultura de uma comunidade e de um grupo como elemento primordial que influencia diretamente a língua, sobretudo, as formas de nomear tudo que faz parte do cotidiano dos sujeitos.

\section{OS MÉTODOS PALAVRAS E COISAS E ONOMASIOLÓGICO}

Nesta seção, apresentamos os métodos Palavras e Coisas e Onomasiológico que foram desenvolvidos no seio da Filologia Românica, no final do século XIX, em oposição ao método Histórico-comparativo que se centrou nos estudos de aspectos gramaticais das línguas.

Por sua vez, derivado da Geografia Linguística, os métodos Palavras e Coisas e o Onomasiológico investigam a oralidade, os aspectos culturais e as vivências dos falantes. Por esse viés, a Filologia também passa a se ocupar da língua oral, deixando de se restringir somente ao texto escrito. Por isso, afirmamos que a Filologia é uma ciência dos textos antigos, mas não apenas. Todo material escrito, independentemente de qual época seja, é também objeto de estudo da Filologia. O texto oral poderá ser transcrito e vigorar como um registro escrito, cabendo, similarmente, no campo de estudo filológico, uma vez que traz a cultura e a história de um povo expressas em seu conteúdo. Esses métodos muito contribuíram para o conhecimento das línguas neolatinas, sobretudo, das variações da fala 
das minorias que moravam nos rincões desconhecidos e suas maneiras de nomear as coisas e suas práticas de trabalho.

À luz desses estudos, buscamos compreender o processo de formação de palavras e as motivações que dão origem a outros vocábulos, relativos às culturas agrícolas estudadas.

O método Palavras e Coisas tem como mentores Hugo Schuchardt e Rudolf Meringer. Para eles, as coisas precedem suas denominações, ao considerarem uma estreita relação entre as coisas e as suas denominações, em que aquelas precedem a estas. Acreditavam que "conhecendo-se a natureza, as medidas, a forma, o uso etc. dos objetos, é possível fixar a origem das palavras com as quais esses mesmos objetos são designados" (BASSETTO, 2005, p. 74).

O método idealizado por Schuchardt e Meringer busca estudar o verdadeiro significado originário das palavras não no étimo, mas através da própria história do vocábulo. Segundo Bassetto (2001, p. 75), "pelo conhecimento em profundidade da "coisa", chega-se ao étimo da palavra que a designa, isto é, o significado correto e originário com que a coisa foi primeiramente nomeada".

Em nosso estudo, os dados obtidos foram analisados considerando esse método, devido às práticas de nomeação das culturas agrícolas do feijão e do milho, aqui estudadas, serem centradas na vivência do mundo real dos agricultores, como faziam os antigos, influenciados pelas atividades corriqueiras da vida que levavam-nos a denominar uma coisa pelas suas vivências, como apresentam alguns autores o caso do vocábulo português fígado. Este vocábulo vem do latim com uma forma muito diferente do que passou a ser (Lat. iecur; ficatum, cast. higado, it. fegato, rom. ficat), pela prática dos gregos de engordar patos e porcos com figos (fruta), com isso, acreditava-se que o fígado desses animais ficava maior e melhor para o consumo, por que não dizer mais gorduroso, saboroso, daí surge a expressão "fígado engordado com figo".

Neste trabalho, para efeito de ilustração, apresentamos aqui um exemplo análogo, a saber: os entrevistados informaram um tipo de feijão denominado "boi deitado", o porquê de tal denominação é sempre o mesmo. Segundo os informantes, o grão desse tipo de feijão assemelha-se a um boi quando está deitado, e, dependendo da posição que é visto o grão, tal semelhança acentua-se mais ainda a figura desse animal. Esse é apenas um dos vários exemplos que poderíamos citar ilustrativamente.

Percebemos que ocorrências dessa natureza são passíveis de análise com base no método Palavras e Coisas, pois as denominações da grande maioria das palavras são feitas por analogia. Isto é, para se chegar ao significado de determinado objeto, é preciso conhecer a história das palavras que denominam esse mesmo objeto, daí a estreita relação entre essas duas realidades.

Esse foi um fenômeno recorrente nas falas dos agricultores entrevistados, que, para nomear a cultura agrícola, indagada, recorre a outro conhecimento prévio de mundo, ou seja, outra coisa animada ou inanimada que dá origem ao nome da coisa perguntada (o feijão 
e o milho). Assim assinala Vidos (2001, p.67), "as coisas vêm em primeiro lugar, e ela existe efetivamente, inclusive por si só, completa e em sua integridade, enquanto a palavra depende dela, está ligada a ela e é um satélite seu”. Podemos perceber que as coisas vêm primeiro e seu nome é atribuído conforme o ser humano a percebe e, para essa percepção, é necessário o conhecimento de mundo, a mundividência, em outras palavras, o meio cultural.

O método Onomasiológico ou Onomasiologia está estreitamente ligado ao método Palavras e Coisas, ambos voltados aos aspectos semânticos dos vocábulos, que tratam da parte dinâmica e viva da língua, percebendo suas mutações e levando em consideração aspetos extralinguísticos, como o modo que o falante ver o mundo e sua cultura vivenciada, não se limitando a meros elementos fonéticos. Como bem aponta Vidos (2001, p.69), o falante "esforça-se por descobrir a vida da linguagem e as forças criativas na língua".

Assim como o Palavras e Coisas, a Onomasiologia é também originária da Geografia Linguística, ambas convergindo em seus objetos de estudo e em suas propostas investigativas centradas no léxico e nas motivações de ordem prática e vivenciadas pelos usuários de uma língua. Para Bassetto (2001, p.76), a Onomasiologia

[...] se propõe investigar os vários nomes atribuídos a um objeto, animal, planta, conceito etc., individualmente ou em grupo, dentro de um ou vários domínios linguísticos. Seus objetivos, portanto, semânticos e lexicológicos, buscando descobrir os aspectos vivos e as forças criadoras da linguagem.

Para esse método da Filologia Românica, não podemos apontar um único mentor ou criador, no entanto, seus princípios foram se desenvolvendo aos poucos, à medida que trabalhos eram produzidos com esse viés investigativo da linguagem, nas suas várias formas de manifestação, refletindo aspectos referentes à cultura, à região, às crenças, às ocupações e aos costumes dos povos.

Somente com Carlo Salvioni e Ernest Toppolet, a Onomasiologia firma seu caráter científico, quando este estudou os nomes românicos de parentesco e aquele, as várias formas de nomear o vagalume na Itália. Foi com essas duas personalidades que os estudos onomasiológicos ganharam uma maior solidez.

Com base nos conceitos aqui apresentados referentes à Onomasiologia, percebemos que nosso corpus é passível de análise mediante também esse método, uma vez que está evidente a proximidade com suas propostas, tendo em vista que, ambos os métodos com base na língua falada, investigam as práticas de nomear as coisas, por motivações variadas.

Pela Onomasiologia, podemos, além de observar a relação entre coisa/palavra, também estabelecer as características e atividades de uma dada região e situá-la no tempo, sendo o léxico o objeto investigativo para se chegar a essa constatação, uma vez que as 
peculiaridades e as marcas sociais são transferidas de geração a geração, assim como são refletidas na linguagem. Pois, como menciona Ximenes (2014, p.51), "a língua é uma das formas mais genuínas de revelar a identidade de uma pessoa ou de um grupo social".

A forma de nomear as coisas com base nos métodos supracitados reflete de seus usuários os conhecimentos culturais e regionais, as práticas, os costumes e suas vivências dentro da própria comunidade. Os reflexos desses fatores sociolinguísticos despontam, por assim dizer, o caráter de organismo vivo, criador e instável que é a língua.

\section{DISCUTINDO LÉXICO E CULTURA}

\subsection{SOBRE O LÉXICO}

O homem, no exercício da comunicação, involuntariamente, categoriza e nomeia as coisas, os seres, os objetos, enfim, tudo aquilo que o circunda. À medida que se dá esse processo involuntário, mas consciente, acaba por gerar os léxicos das línguas de forma natural, onde esse processo se dá por atos que se sucedem cognitivamente com base nas coisas do mundo real e empírico. E o resultado desses processos de categorizar e nomear as coisas se cristaliza por meio do signo linguístico.

Seguindo essa linhagem podemos afirmar que o léxico ao mesmo tempo em que categoriza e nomeia a realidade mundana, também sintetiza o modo como os falantes veem essa realidade, deixando transparecer valores, crenças, hábitos e costumes de um grupo social.

Cumpri (2012, p. 42), fazendo algumas reflexões sobre o léxico, nos traz a seguinte definição: "[...] além de o léxico ser a forma de registrar o conhecimento do universo, também é um sistema aberto que engloba o patrimônio vocabular de uma dada comunidade linguística ao longo de sua história, que constitui um tesouro cultural abstrato".

Aqui empregamos o conceito de léxico sob a perspectiva sociocultural, em que se analisa o emprego do item lexical como prática social que revela a cultura de uma comunidade para que assim haja um enquadramento dentro da nossa proposta de estudo. Desse modo, ao concebermos o léxico com base nessa perspectiva, isto é, investigar a realização da língua por meio da nomeação das coisas, inevitavelmente, conhece-se a cultura dos investigados.

Esse é um fato pertinente aos dados coletados para composição do corpus, visto que a prática de nomear as culturas agrícolas aqui estudadas se apresenta como algo típico e cultural da região investigada, que perpassa gerações, hábito transmitido aos sucessores. Nesse sentido, Barros e Isquerdo (2010, p. 74) nos apresentam um conceito para o léxico muito peculiar a nossa investigação, "o léxico é social, porque se fundamenta em uma análise continuada das situações em que ocorre um ato de fala". 
Birderman (1996) segue essa mesma linhagem, quando defende a ideia de que o léxico está em perpétua mutação e movimento, acompanhando as mudanças socioculturais. Assim como Ximenes (2014, p.52) que, com bastante objetividade, define o léxico como "um conjunto de vocábulos ou palavras de que dispõe uma língua para realizar suas necessidades de comunicação diária".

Partindo desse pressuposto e com base nessas acepções defensoras do léxico como sendo unidade linguística mutável, social e comunicativa, faremos a nossa análise do corpus aqui estudado, fundamentado e baseado nessa ideia.

Destarte, podemos afirmar que as palavras, ou melhor, o léxico materializa aspectos da realidade de uma dada localidade ou região, no nosso caso, as formas de nomear as culturas agrícolas do feijão e do milho no município de Ocara, o que justifica estudos pontuais, evidenciando o tripé léxico-cultura-sociedade.

\subsection{SOBRE CULTURA}

Assim como o léxico, atribuir um conceito à cultura não é tarefa fácil, devido à complexa distinção semântica que o vocábulo engloba. Aqui não nos cabe esgotar os diversos conceitos do termo, como também não é nossa intenção apresentar respostas completas sobre o que venha a ser cultura.

No entanto, é nossa tarefa fazermos algumas observações semânticas sobre o termo cultura, voltadas à nossa proposta de estudo, isto é, cultura em seu sentido originário da palavra relativo ao cultivo de produtos agrícolas. Assim como também no sentido de costumes e práticas sociais abarcadas pelo termo.

Chaui (2000 p. 372) menciona sobre a significação inicial da noção de cultura, "vinda do verbo latino colere, que significa cultivar, criar, tomar conta e cuidar, cultura significava o cuidado do homem com a Natureza". Dessa forma, cultura, no sentido originário do termo, se volta para os cuidados que o homem presta à natureza, com as práticas agrícolas, com o cultivo de produtos agrários, assim como também para nomear produtos advindos da colheita da terra. Esse conceito primário atribuído ao vocábulo cultura, aqui nos é bastante peculiar, visto que tratamos das formas de nomear produtos (culturas) agrícolas (feijão e o milho), como também das motivações às quais essas nomeações das culturas aqui em voga.

Como já frisamos, essa é apenas uma das atribuições dadas ao termo cultura, dentre a complexa distinção semântica inerente ao tema. Outro viés semântico que trataremos aqui é relativo ao sentido de costumes e práticas sociais, isto é, o todo complexo de conhecimentos e toda habilidade humana empregada socialmente e, em nosso caso específico, atentando ao uso da linguagem e seus mecanismos constitutivos para o exercício da comunicação. 
Compreendendo cultura como sendo um conjunto de práticas, de técnicas, de símbolos e de valores que garantem a convivência social, temos um exercício exclusivo da atividade humana, ou seja, tudo que é cultural é também humano, sendo que uma das formas de manifestar esses aspectos culturais se dá através da língua. Encontramos essa ideia de cultura enquanto manifestação eminentemente humana e, consequentemente, manifestada por meio do signo linguístico. Também para Chaui (2000, p. 61), "a cultura se realiza porque os humanos são capazes de linguagem, trabalho e relação com o tempo. A Cultura se manifesta como vida social, como criação das obras de pensamento e de arte, como vida religiosa e vida política".

Seguindo essa linhagem, aqui buscamos entender e ao mesmo tempo fazer algumas digressões justamente sobre essas influências culturais que vão ao encontro da linguagem, em especial da localidade e das pessoas aqui estudadas, levando em consideração as práticas e os conhecimentos de mundo dessas pessoas, bem como os fatores regionais que, de certa forma, acreditamos influenciar diretamente nas formas de nomear as coisas, como, por exemplo, quando o entrevistado nomeia um tipo de feijão como "rabo de tatu" e não "rabo de tartaruga".

Os fatores motivacionais são tanto de ordem pragmática de conhecimento de mundo, quanto de natureza cultural. Como assim? Defendemos que o que o faz escolher o tatu em vez da tartaruga é o fato de o tatu está mais próximo da realidade do falante e, consequentemente, pertencer à região e à cultura em que este [homem] habita, permitindo-lhe, assim, uma associação mais fiel e empírica a sua realidade. Não faria sentido adotar a tartaruga para nomear o tipo de cultura agrícola cultivada na região, mesmo que a tartaruga seja do conhecimento do agricultor, no entanto, o habitat natural desse animal está distante ou fora da realidade do falante.

Com isso, afirmamos que o fator cultural, enquanto vivência de mundo e formas de representar o mundo conhecido, é fundamental para o ser humano estabelecer elos comparativos abstraídos do seu meio, das coisas conhecidas para atribuir e nomear outras coisas.

\section{ALGUMAS CONSIDERAÇÕES SOBRE OS DADOS}

Como já mencionado anteriormente, coletamos o material para composição do corpus. Muito embora nosso trabalho não tenha cunho fonético, ao fazermos a transcrição, escolhemos por registrar as lexias da forma como pronunciada pelo entrevistado, muitas vezes, utilizando-nos de expressões do próprio entrevistado nas designações dos vocábulos.

Constatamos que as motivações para nomear as culturas aqui em voga são originadas por motivos variados, que vão desde o formato ou cor do grão, perpassando pela 
ramagem ou caule da planta; pelo pendão (vargem) onde ficam os grãos; pelo tempo de duração para colheita; pelo nome de pessoas e até mesmo por alguma especificidade do próprio tipo de cultura (feijão ou milho), por exemplo: o "milho massa” que tem esse nome por ser um tipo de milho macio, que apresenta certa maciez no grão quando esse é esmagado, é um milho "macento" na expressão do entrevistado.

Aqui alocamos os tipos de culturas nomeados conforme a narrativa dos informantes, organizados de acordo com sua natureza motivacional que supostamente deu origem a esses nomes. Posteriormente, com base nos métodos aqui aplicados, faremos algumas observações a respeito daquilo que acreditamos motivar essas formas de nomear tais culturas. Enumeramos da seguinte forma:

\section{a) cor do grão (caroço)}

"Feijão carrapicho branco"; "feijão carrapicho vermelho"; "feijão pingo-de-ouro"; "milho branco"; "milho vermelho".

\section{b) Características ou especificidades da cultura agrícola}

"Feijão brejo da Paraíba"; "feijão sempre verde"; "feijão manteiga"; "milho da âncar"; "milho comum"; "milho massa"; "milho de pipoca"; "milho gordura".

\section{c) Formato do grão (caroço)}

"Feijão barrigudo"; "feijão boca-preta"; "feijão cabeçudo"; "feijão canapum"; "feijão figo-degalinha"; "feijão lisão". "Milho alho".

\section{d) Formato do pendão (vargem) onde ficam os grãos}

"Feijão baja mole"; "feijão costela-de-vaca"; "feijão chifre-de-carneiro"; "feijão rabo-de-tatu".

\section{e) Nome de pessoas}

"Feijão Chico Elóia"; "feijão Mané de Souza".

\section{f) Ramagem ou caule da planta}

"Feijão de corda"; "milho anão".

\section{g) Grão com semelhança a animal}

"Feijão boi deitado"; "feijão corujinha".

\section{h) Tempo para colheita}

"Feijão custoso"; "feijão 40 dias"; "milho ligeiro"; "milho custoso".

Vale a ressalva de que essa classificação motivacional acima não é algo estanque, organizamos dessa forma para fins didáticos, pois algumas das denominações arroladas poderiam estar presentes em mais de uma natureza motivacional, como o tipo de feijão denominado "corujinha", que tanto poderia estar na motivação cor quanto na motivação semelhança com animal.

Outro exemplo que podemos registrar seria o tipo de feijão denominado "lisão", que alocamos de natureza motivacional formato do grão, no entanto, nada impede de 
classificarmos esse tipo de feijão na motivação que denominamos de características on especificidades da cultura agrícola, pois esse feijão, segundo o informante, é "caroço grandão, liso e espelhado, que escorre na palma da mão com facilidade"; essa informação do agricultor pautada no formato do grão também não deixa de ser uma característica inerente a esse tipo de cultura.

Seguindo essa mesma linhagem de perceber a motivação referente às características ou às especificidades da cultura agrícola, temos os tipos de feijão "brejo da Paraíba", "feijão sempre verde" e "feijão manteiga". No primeiro caso, o agricultor não soube informar com precisão o porquê de tal denominação, mas cogitou a ideia de ser um tipo de feijão mais resistente ao brejo, a terrenos onde há uma concentração maior de umidade. No segundo ("feijão sempre verde"), apontou como causa tanto o fato de ser o grão de tonalidade verde, mesmo estando bem maduro quando colhido, como também o fato da ramagem da planta demorar mais tempo que os demais tipos para secar, permanecendo esverdeada. E por último ("feijão manteiga"), pelo fato de ser um feijão que tem muita facilidade de cozinhar, não demanda muito tempo, como também por ser macio durante a degustação. Poderíamos fazer uma classificação diferente, no entanto, preferimos a forma apresentada, para facilitar o entendimento e a aplicabilidade dos métodos filológicos que norteiam as formas de nomear as culturas agrícolas aqui estudadas.

Pelo exposto até aqui, nos cabe fazer algumas reflexões acerca dos nomes do feijão apresentados pelos agricultores informantes. Como vemos, as formas de dar nomes a essas culturas surgem de motivações de natureza variada. Assim sendo, como forma explicativa, elegemos algumas dessas culturas para justificarmos a aplicação dos métodos filológicos escolhidos, por serem bem peculiares a estes. Faremos também algumas observações que nos levaram a certas indagações, em que tentamos, de certa forma, respondê-las, com base tanto nos métodos como também na visão de mundo e no conhecimento empírico dos entrevistados.

Nas respostas dos agricultores, podemos conferir uma analogia para denominar um tipo de feijão que o entrevistado nomeou de "boi deitado", e ao ser perguntado o porquê de se chamar dessa forma, explicou que o grão (caroço) se assemelha bastante a figura de um boi quando este está deitado, conforme já mencionamos acima. Nesse caso, poderíamos lançar o seguinte questionamento: por que o agricultor nomeia esse feijão de boi deitado e não "búfalo deitado"? O que justificaria tal escolha, o boi em vez de búfalo?

Nossa resposta se pauta no sentido de que esse processo de nomeação de uma dada coisa advém de outra coisa preexistente, visto que a existência desta proporciona a nomeação daquela. Mas aqui nos cabe a observação de, quando o usuário da língua recorre a essa prática de atribuir nome ao até então inominado, faz isso levando em consideração aquilo que está mais ao seu alcance, isto é, apoiado no seu conhecimento de mundo empírico, social e cultural. Portanto, a figura de um boi deitado para um morador da zona 
rural do município de Ocara é bem mais peculiar que a de um búfalo, pois o boi faz parte de sua realidade social e cultural. Com certeza, esse agricultor já presenciou em algum momento da vida esse animal deitado, permitindo-lhe assim a associação, já o búfalo não é da realidade empírica da pessoa entrevistada, acreditamos que esse é um fator determinante que impossibilita a escolha de boi ao invés de búfalo.

Em muitas formas de nomear as culturas aqui em voga, poderíamos fazer essas mesmas indagações do porquê da escolha de determinada coisa, objeto ou animal e não por outra coisa similar à escolhida pelo entrevistado. Por exemplo, quando o falante nomeia um tipo de milho de "milho gordura" e não "milho azeite", defendemos também que essa escolha é motivada pelas mesmas razões que nomeou o tipo de "feijão boi deitado", mencionado anteriormente. Com a ressalva de que, ao escolher a lexia gordura, percebemos que não se trata de qualquer tipo de gordura, pois necessariamente deve ser um tipo que esteja concentrada numa tonalidade amarelada, típico de gordura extraída de suíno, pois o milho é na expressão do entrevistado: "amarelim, espelhado e liso como se estivesse melado com algo gorduroso". Já a lexia az̧eite não é típica do vocabulário do ocarense, tampouco o produto lhe é familiar. Destarte, levando em consideração aspectos culturais e regionais, o azeite, de certa forma, para o entrevistado, torna-se algo de maior requinte, mais moderno, preferindo, assim, nomear o tipo de milho analogamente a algo mais próximo de sua realidade social.

Esses fenômenos percebidos por meio dos dados colhidos justificam, por assim dizer, a aplicabilidade dos métodos filológicos Palavras e Coisas e Onomasiológico aqui focalizados, por estes investigar, com base no léxico, as formas de nomear algo a partir da existência de uma dada coisa que serve como parâmetro para o surgimento de outro vocábulo. Como podemos observar explicitamente na forma de nomear o "feijão canapum". O canapum é uma fruta típica da região que nasce em meio à pastagem e se caracteriza pela forma arredondada similar a uma bola de gude. Portanto, o agricultor já conhecendo esse tipo de fruta, associa o grão de feijão à frutinha, por analogia.

Percebemos que o usuário não só se utiliza da existência de coisa material, mas também de outros recursos percebidos a partir do comportamento da cultura agrícola aqui investigada. Por exemplo, quando nomeia o feijão e o milho tendo como parâmetro o tempo: "feijão custoso", "feijão 40 dias", e "milho custoso", "milho ligeiro", esse é mais um artifício inteligente utilizado pelo falante da língua de dar nome ao que precisa ser nomeado, para estabelecer o processo de comunicação entre os seus membros dotados de linguagem. Esse recurso não foge aos métodos propostos, visto que o tempo também é uma coisa, mesmo estando no plano abstrato do pensamento.

Algumas características específicas de determinada coisa ou objeto são também motivadoras de se constituir nomes aos tipos de culturas agrícolas presentes no corpus, é o que podemos observar quando se nomeia os tipos de "feijão baja mole", "feijão chifre-de- 
carneiro", "feijão costela-de-vaca" e "feijão rabo-de-tatu". Todos eles motivados pelo formato característico em que se dá o pendão/baja (vargem) onde ficam os grãos ainda em fase de crescimento. Essa maneira de nomear tais culturas nos remete a uma ideia imagética do contorno em que se dá a formação desse pendão (vargem), quando nos vem à mente o formato de um chifre de carneiro e de uma costela de bovino, isto é, para o chifre do carneiro, a vargem ganha uma envergadura acentuada a ponto de formar duas pontas, remetendo a ideia de chifres; já para a costela de vaca, imagina-se a vargem bastante alongada, comprida e encurvada.

A perspicácia do homem do campo não para por aí quando se trata da necessidade de nomear os tipos de cultura que produz, pois dois tipos de feijão foram nomeados por nome próprios de pessoas, quais sejam: "Feijão Chico Elóia” e "Feijão Mané de Souza", sendo que o primeiro foi citado por três dos entrevistados e o segundo somente uma vez por um deles.

Nesse caso específico, ao ser indagado por tais denominações, houve uma pausa em meio a uma dúvida, sendo que nenhum dos entrevistados soube dar uma explicação mais precisa das razões que levariam à nomeação desse feijão. Apenas os agricultores mencionavam que conheciam por esses nomes, mas não sabiam o porquê. No entanto, em meio à interação envolvendo perguntas e respostas, cogitamos a hipótese de que tais nomes próprios atribuídos a esses tipos específicos de feijão vêm do fato de alguém com esses nomes, outrora, terem trazidos as sementes e terem disseminado na região. Percebemos que a todos os agricultores essa cogitação fez sentindo, porque não discordavam da hipótese levantada.

A ramagem ou caule da planta também é motivo para nomear uma espécie de feijão e um tipo de milho, respectivamente, "Feijão de corda" e "Milho anão". No primeiro caso ("feijão de corda"), segundo o agricultor, as ramagens ou galhos da planta se espalham pelo chão alcançando longa distância, por isso são associados a uma corda de grande extensão. Já no caso do "milho anão" segue o inverso, isto é, o caule da planta não alcança grande estatura. Na expressão do agricultor "não cresce muito", essa ideia é associada para dar nome ao tipo específico dessa cultura agrícola. Outra informação adicional mencionada pelo camponês a respeito desse tipo de milho foi a de que, apesar da planta não crescer muito, tem espigas pequenas, mas carregadas e compactadas com muitos grãos.

Todas essas observações e exemplos postos nessa etapa de nosso trabalho são exemplificativos e, ao mesmo tempo, servem como demonstração para todas as demais lexias presentes no corpus, isto é, as diversas formas de se nomear as culturas agrícolas aqui em foco, buscando sempre uma fonte originária de natureza variada para a constituição de um novo vocábulo. Esse fenômeno nos mostra a eficácia dos métodos filológicos inclusos a nossa investigação, como no caso da Onomasiologia responsável por revelar a cultura de um povo em uma dada região, a partir dos fenômenos inerentes à linguagem, 
atentando para os costumes, as ocupações, as crenças e a própria língua. Assim como também, a presença maciça das formas de nomear as culturas com base no método Palavras $e$ Coisas, tendo em vista, uma prática mais bem fundamentada que outras, contudo, todas elas buscando uma denominação vocabular a partir da estreita relação palavra/ objeto.

Esse é um fato que demonstra não só a necessidade vital de nomear determinadas 'coisas' para diferenciá-las entre as demais, como também o caráter criativo do usuário da língua, estimulado justamente por essa necessidade de nomear e comunicar. $O$ mais interessante é que essa tentativa de distinção, a partir da nomeação, realiza-se com bastante clareza e objetividade, alcançando-se, assim, o objetivo de estabelecer a comunicação em meio ao grupo ao qual o falante está inserido.

Por último, registramos um fato que julgamos relevante para a nossa pesquisa: apesar da diversidade, houve a constante repetição no processo de nomear as culturas agrícolas focadas, seja para denominar os tipos de feijão, seja para denominar os tipos o milho. Por exemplo, temos o tipo de "feijão carrapicho branco" mencionado por todos os agricultores e o "milho gordura" repetido por cinco entrevistados. Esse fato da repetição nas formas de nomear as culturas aqui investigadas, a nosso ver, é bastante positivo, visto que há uma convergência nos dados coletados interligando-os, pois nossa pesquisa se limita a algumas comunidades rurais de um mesmo município (Ocara), e esse fato demonstra a interação entre os agricultores.

\section{CONSIDERAÇÕES FINAIS}

Neste trabalho nos propusemos a fazer uma breve análise filológica do léxico referente às formas de nomear as culturas do feijão e do milho, a partir de dados coletados através de entrevistas realizadas com 6 agricultores do município de Ocara, que têm a agricultura como profissão.

No primeiro momento, apresentamos o objetivo de nossa pesquisa, em seguida como se desenvolveu a constituição do corpus coletado (por meio de entrevistas de campo), trouxemos os métodos filológicos aplicados a nossa investigação: palavras e coisas e Onomasiológico, como também expusemos conceitos de léxico e de cultura. Posteriormente, fizemos uma classificação conforme a natureza motivacional de cada tipo de cultura. Procurando ser o mais fiel possível aos preciosos dados coletados, apresentamos a transcrição dessas informações, por meio do corpus (anexo a este trabalho), como também nossas considerações com base no léxico e apoiado nos métodos supracitados.

Nesta última parte, nos cabe uma breve reflexão a respeito da pesquisa e dos dados levantados. Assim sendo, baseados nos resultados obtidos, podemos afirmar a relevância de uma pesquisa dessa natureza.

Os dados nos mostram uma evidência no que diz respeito aos estudos relativos ao 
código linguístico, ou seja, que a língua é constituída e construída pelos falantes, por seus usuários, que, com a necessidade de comunicar, utilizam recursos para melhor utilizá-la. É o que nos aponta Antunes (2010, p.60-61): "Na verdade, é o usuário da língua quem conhece o caráter significante e significador da linguagem".

Vimos também que o usuário da língua, ao utilizar-se desta para a prática da comunicação, não a utiliza de maneira aleatória ou desconexa, isto é, os dados atestam que as pessoas, no ato de nomear as coisas, não fazem isso de maneira ignorante, mas sim de forma consciente e por que não dizer de maneira acertada, como no caso de nossa investigação, nas formas de nomear as culturas aqui pesquisadas, é notória a estreita relação entre o nome (palavra) com a coisa (objeto) relacionada.

Portanto, a necessidade de nomear as coisas é feita conscientemente e de maneira inteligente pelo usuário da língua, utilizando-se de analogias, exemplificadas e atestadas em nossa pesquisa. Esse é um recurso muito recorrente, sobretudo, quando há a necessidade de nomear algo novo, mas também em comunidades que desconhecem as origens etimológicas de determinados vocábulos (palavras) envolvendo léxicos variados.

Assim, sabiamente, as pessoas nomeiam as coisas, que ganham validade inquestionável e são perfeitamente aceitas, utilizadas e disseminadas entre seus usuários. Nesse preciso sentido, a língua é tida como uma forma de ação social e histórica que, ao dizer, também constitui uma realidade.

Esse objeto de estudo tão dinâmico e interessante, chamado língua, permite que seus usuários se apropriem dela e que até possam moldá-la, com o objetivo exclusivo de estabelecer a comunicabilidade, seja por analogias, seja por outras técnicas de se constituir a comunicação necessária entre seus falantes.

Ao estudioso da linguagem, cabe a atividade de estudar e registrar tais ocorrências, que servirão de fontes para os diversos ramos da ciência, pois a língua é um elemento vivo e presente em todos os setores sociais e científicos.

\section{REFERÊNCIAS BIBLIOGRÁFICAS}

ANTUNES, Irandé. Análise de Textos: fundamentos e práticas. São Paulo: Parábola, 2010.

BARROS, L. A.; ISQUERDO, A. N. (Orgs.). O léxico em foco: múltiplos olhares. São Paulo: Cultura Acadêmica, 2010.

BIDERMAN, M. T. C. Léxico e vocabulário fundamental. Alfa, São Paulo, v.40, 1996. p.27-46. Disponível em: <http://piwik.ser.fclar.unesp.br/alfa/article/download/3994/3664>. Acesso em: 30 maio 2017.

CHAUI, Marilena: Convite à Filosofia. São Paulo: Ática, 2000.

CUMPRI, M. L: Algumas reflexões sobre léxico e gramática. Entrepalavras, a.2, v.2, n.1, , Fortaleza, jan./jul., 2012. p.41-50. Disponível em: <http://www.entrepalavras.ufc.br/revista/index.php/Revista/article/viewFile/41/90 . 
Acesso em: 30 maio 2017.

HOUAISS, Antonio; VILLAR, Mauro Salles. Dicionário Houaiss de Língua portuguesa. Rio de janeiro: Objetiva, 2001.

SANTOS, J. L. O que é Cultura. 16.ed. São Paulo: Brasiliense, 2006 [1996]. p.110. (Coleção primeiros passos).

VIDOS, B. E. Manual de Linguística Românica. 2.ed. corrig. e atual., v.1. Tradução de José Pereira da Silva. [S.1.]: do Tradutor, 2001. (História e Metodologia).

XIMENES, Expedito Eloísio. Léxico e cultura: as influências sociais nas formas de nomeação. In: SILVA, Francisco Carlos Carvalho da; SILVA, Isaíde Bandeira da; TAHIM, Makarius Oliveira (Orgs.). Sociedade, ciência e sertão: reflexões sobre educação, história, cultura e tecnologias. Fortaleza: EDUECE, 2014.

Recebido em: 17/05/2017

Aprovado em: 25/08/2017

Publicado em: 01/12/2017 